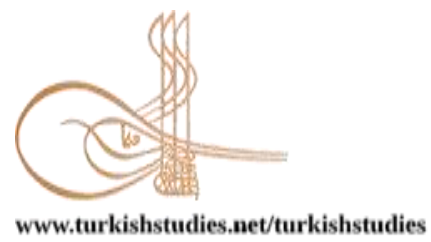

Turkish Studies

\title{
Bireysel ve Takım Sporlarındaki Antrenörlerin Liderlik Davranışları Yönelimlerinin Bazı Değişkenlere Göre Belirlenmesi (Sakarya İli Adapazarı İlçesi Örneği)
}

\author{
Determining The Leadership Behavior Orientation Of Coaches In Individual And Team Sports \\ According To Some Bariables (Example of Sakarya Province Adapazarl District)
}

\author{
Fuat Orkun Tapşın* - Betül Bayazıt** - Ahmet Aydemir ${ }^{* * *}$ - Faik Orhun Tapşın ${ }^{* * * *}$
}

\begin{abstract}
The aim of this research is to determine the leadership behavior orientation of the coaches in individual and team sports. This descriptive research is the study of the leadership orientation of individuals who train in the private sports centers in the Adapazarı district of Sakarya province, regardless of the sports branch, and the research population is those who train in private sports centers in the district of Adapazarı in Sakarya Province. The study consisted of 180 people, 55 (30.6\%) women and 125 (69.4\%) men, who were trained in private sports centers, who were reached by random method and agreed to participate in the research voluntarily. In the research, developed by Bolman and Deal (1990) and adapted to turkish by Dereli (2003) "Leadership Orientation Scale" was used with a personal information form. SPSS 20.0 package program was used to analyze the data. When the result of the research is examined, in the light of the data obtained; when the leadership orientations of individual and team sports coaches were examined, there was no significant difference in age and gender ( $p>0.05$ ). In the economic situation variable, a significant difference was found in the structure-oriented leadership and charismatic leadership sub-dimension $(\mathrm{p}$ $<0.05)$. As a result of this study, it was concluded that the structure-oriented and charismatic leadership characteristics of the individuals who train in private sports centers are affected by the economic situation. It has been concluded that the economic situation is important for the coach to create a strong vision in the development of charismatic and structural leadership and to develop features such as command command and division of labor.In order to conduct this research, the ethics committee approval was obtained with the 5
\end{abstract}

*Doktora Öğrencisi, Kocaeli Üniversitesi, Sağlık Bilimleri Enstitüsü

PhD Student, Kocaeli University, Institude of Health Sciences

ORCID 0000-0001-6374-534X

fuat_orkun@hotmail.com

** Doç. Dr., Kocaeli Üniversitesi, Spor Bilimleri Fakültesi, Rekreasyon Bölümü

Assoc. Prof. Dr., Kocaeli University, Faculty of Sports Sciences, Department of Recreation

ORCID 0000-0003-3547-2035

betul.bayazit@kocaeli.edu.tr

**** Doktora Öğrencisi, Kocaeli Üniversite, Sağlık Bilimleri Enstitüsü

PhD Student, Kocaeli University, Institude Of Health Sciences

ORCID 0000-0002-6778-4175

ahmetaydemir1904@gmail.com

***** Doktora Öğrencisi, Gazi Üniversitesi, Sağl1k Bilimleri Enstitüsü

PhD Student, Kocaeli University, Institude of Health Sciences

ORCID 0000-0002-7099-6929

tpsnorhun@gmail.com

Cite as/ Atıf:Tapşın, F. O., Bayazıt, B., Aydemir, A. \& Tapşın, F. O. (2020). Bireysel ve takım sporlarındaki antrenörlerin liderlik davranışları yönelimlerinin bazı değişkenlere göre belirlenmesi (Sakarya ili Adapazarı ilçesi örneği). Turkish Studies, 15(5), 2625-2636. https://dx.doi.org/10.7827/TurkishStudies.43572

Received/Geliş:14 May/Mayıs 2020

Accepted/Kabul:25 August/Ağustos 2020

Checked by plagiarism software

Copyright $\odot$ MDE, Turkey

Published/Yayın: 31 August/Ağustos 2020

CC BY-NC 4.0 
order decision of Kocaeli University Social and Human Sciences Ethics Committee dated 27/02/2020 and numbered 2020/3.

Structured Abstract: The main goal of leadership is to provide individuals with the confidence to express themselves, to adapt to different situations, and to gain the ability to ask and question. Achieving this requires thinking. For this reason, it is necessary to support trend programs, which are the basis of reason and science. Today, there are many reasons that require leadership orientation in order to achieve short and longterm goals, which should be protected from unwanted movements while giving sports education, as in all academic fields of society (Cengiz and Güllü, 2018). The concept of leadership is as old as human history. Human beings tend to survive as a social being. This trend has laid the groundwork for the formation of structures where there is interaction at different levels, starting from groups to societies. In cases of partnerships where there is interaction, some individuals may be more dominant, more prominent than others, and become leaders with the approval of other individuals in the group. In this way, leadership is a result of the interaction between the individual who is a leader and other individuals and a responsibility that the individual takes on differently from other individuals within a specified community. In a different saying, it is said that the individual in the group is a type of behavior that the group exhibits (Tekin and Zorba, 2017). Leadership is a fundamental aspect of sports performance in team and individual sports settings. There have been important studies investigating the role of the coach in this regard. Coaches have a significant impact on a number of factors related to the team, including their formal (captain) and informal (such as motivational and cultural architects) role, satisfaction, harmony and team dynamics. As a team leader, a coach plays an important role in achieving a high level of performance and success for his players; therefore, a coach should have the skills to help his athletes perform such difficult tasks. Therefore, the mechanisms by which this effect occurs must be better understood (Cotterill and Fransen 2016).

The coaching leadership behavior is a behavioral process in which an individual or group can be affected in order to achieve the set goals. The coach's role is to help the athlete achieve sufficient individual and team performance in competitive efficiency. During the training preparation and competition process, the coach has the task of directing the athlete to reach the specified goals. The motivation and performance quality of the athlete develops and changes under the influence of many factors. The personality of the trainer, his competitive experience, competitive success, ability to transfer information can have a significant impact on the success of an individual athlete in elite sports (Trninic et al., 2009).

The aim of this study is to examine the leadership orientations of individuals who train in the Adapazarı district of Sakarya, regardless of the sports branch. In order to conduct this research, the ethics committee approval was obtained with the 5 order decision of Kocaeli University Social and Human Sciences Ethics Committee dated 27/02/2020 and numbered 2020/3.

In this study, which aims to determine the leadership orientation of the individuals who train at the private sports centers in the Adapazarı district of Sakarya province, a total of 180 people, 55 (30.6\%) women and $125(69.4 \%)$ men, were included in the study. The research was carried out by random method and on the basis of volunteering, no information was given about which sports branch the coaches were coaching. The research is limited to private sports centers in Adapazarı district of Sakarya province. In the evaluation of the study data; descriptive statistics such as frequency, number, standard deviation were used. Since the data were normally distributed, parametric tests were applied and independent $t$ test was used for binary sets comparison for independent variables and Anova test was used for more than two comparisons, and Scheffe test used to analyze the results correctly.

Keywords: Sports, Coach, Leadership, Leader, Coaching

Öz: Bu araştırmanın amacı, bireysel ve takım sporlarındaki antrenörlerin liderlik davranışları yönelimlerinin belirlenmesidir. Betimsel olan bu araştırma, Sakarya ilinin Adapazarı ilçesindeki özel spor merkezlerinde antrenörlük yapan bireylerin spor branşı gözetmeksizin liderlik yönelimlerinin incelenmesi olup araştırma evreni ise Sakarya İlinin Adapazarı ilçesindeki özel spor merkezlerinde antrenörlük yapan kişilerdir. Bu araştırmanın yapılabilmesi için Kocaeli Üniversitesi Sosyal ve Beşeri Bilimler Etik Kurulu’nun 27/02/2020 tarihli, 2020/3 nolu ve 5 sıra sayılı kararı ile etik kurul onayı alınmıştır. Çalışmada özel spor merkezlerinde antrenörlük yapan kişiler rastgele yöntemle ulaşılan ve araştırmaya gönüllü katılmayı kabul eden 55'i (\%30.6) kadın, 125'i (\%69.4) erkek olmak üzere toplam 180 kişiden oluşmaktadır. Araştırmada, kişisel bilgi

Turkish Studies, 15(5) 
formu ile Bolman ve Deal tarafından (1990) yılında geliştirilen ve Dereli (2003) tarafindan Türkçeye uyarlanan "Liderlik Yönelimleri Ölçeğì" kullanılmıştır. Verilerin çözümlenmesinde SPSS 20.0 paket programı kullanılmıştır. Araştırmada elde edilen bulgular doğrultusunda; bireysel ve takım sporu antrenörlerinin liderlik yönelimlerinde, yaş ve cinsiyet değişkeni açısından anlamlı bir farklılık bulunmazken ( $p>0.05$ ) ekonomik durum değişkeninde yapıya yönelik liderlik ve karizmatik liderlik alt boyutunda anlamlı bir farklılık olduğu bulunmuştur $(\mathrm{p}<0.05)$. Bu çalışmada, özel spor merkezlerinde antrenörlük yapan bireylerin liderlik yönelimlerinin gelişiminde yapıya yönelik ve karizmatik liderlik özelliklerinin ekonomik duruma bağlı olarak etkilendiği ortaya çıkmış olup karizmatik ve yapıya yönelik liderliğin gelişiminde antrenörlerin güçlü bir vizyon oluşturabilmesi için emir komuta, iş bölümü gibi özelliklerinin gelişebilmesinde de ekonomik durumun önemli olduğu sonucuna varılmıştır.

Anahtar Kelimeler: Spor Antrenör, Liderlik, Lider, Antrenörlük

\section{Giriş}

İnsanlar toplumsal bir ortamda sürekli ve çeşitli davranışlar göstermektedir.Bu davranışlar insanların hareket etmelerinden kaynaklı en önemli karakteristik özelliklerinden biridir. Bu özellikler toplumsal ilişkilerinde, yaşamı idame etme çabasında, rekreasyonel faaliyetlerde ve dinlenme etkinliklerinde görülür. Her insanın ve her canlının belli amaçları vardır. Bu amaçlar varlığı denge ve uyum içinde sürdürmektir. İnsanlar denge ve uyumun yanında sağlıklı kalabilmek için hareket etme ihtiyacı güderler. Hareket insana fizyolojik, psikolojik ve sosyal gelişimine katkı sağlayan bir unsurdur (Doğan, 2015: s15).Spor, birçoğunun hayatında büyük ve önemli bir rol oynar. Her yaştan sporcu antrenörler tarafindan yönetilir ve bu da sporcular üzerinde önemli bir etkiye sahiptir. Bununla birlikte, sporcuların antrenörlerden ne bekledikleri ve antrenörlerin kendilerini nasıl algıladıkları beklentileri ile birlikte etki düzeyi bilinmemektedir (Williams ve Krane, 2015). Antrenörün rolü oldukça karmaşık bir süreç olarak kabul edilir. Çoğu ortamdaki antrenörler, planlama uygulamaları ve oyun stratejileri, organizasyonel görevler, temel becerileri ve taktikleri öğretmekten daha fazlasını içeren çeşitli görevleri tamamlamalıdır (Chelladurai, 1984).

Lider bir antrenörün rolü, sporcunun bireysel ve takım performansı rekabet etkinliğine ulaşmasına yardımcı olmaktır. Antrenörün liderlik davranışı, belirlenen hedeflere doğru çabalayan bireyi ve grubu etkileme süreci olarak tanımlanabilir (Riemer ve Chelladurai, 1998).Antrenörün kişiliği, deneyimi ve bilgi aktarma yeteneği sporcunun başarısı üzerinde önemli bir etkiye sahiptir. Antrenör, liderlik davranışıyla birlikte sporcuların motivasyonunu, performansını ve rekabet etkinliğini etkileyen önemli bir durumsal faktördür. Antrenörler yarışmalarda sporcuları yönlendirmek için önemli olan bazı özelliklere işaret etmektedir. Bunlar sistematik, kalıcılık, inovasyon, liderlik yetenekleri, liderlik stili, uzman bilgisi, pedago-psikolojik yetenekleri ve sezgisidir (Kajtna ve ark., 2007). Antrenörler, sosyokültürel bir ortamda başkalarının tutum ve davranışlarını etkileme veya değiştirme yeteneğine sahip oldukları ölçüde güce sahiptirler. Antrenörlük etkinliği üzerine yapılan çoğu araştırma, antrenörlerin sporcuların performansını, davranışlarını, psikolojik ve duygusal refahlarını büyük ölçüde etkilediği belirtilmiştir (Şahin, 2011).

Antrenörler gibi önemli spor paydaşlarının davranışları sporcularının tercihlerine uymadığında sporcular üzerinde olumsuz bir etkiye sahip oldukları bulunmuştur (Gould ve ark., 1996).Sporcuyu kendi perspektifinden nasıl gördüklerini doğru bir şekilde iletebilen bir antrenör, sporcuları tarafından daha özgün olarak algılanacaktır (Szedlak ve ark., 2015).Antrenörler arasındaki özgünlüğün algı üzerinde önemli bir etkisi olduğu belirtilmiştir (Chelladurai, 1978). Bir sporcunun performansı, sporcu ve antrenör arasındaki etkili iletişim ile artabilir.Çünkü bir antrenör sporcularıyla iletişiminin yaş, cinsiyet ve sosyal statüdeki sporcular üzerinde etkisi olduğu ifade edilmektedir (Katz ve Kahn, 1978). Bir antrenörün, antrenörlük davranışıyla ilgili öğreticiliği, yönlendiriciliği belirli bir sporun becerilerini, tekniklerini ve taktiklerini öğreterek, sporcuların rollerini ve karşılıklı görüşlerini netleştirerek sporcuların performansını iyileştirmeyi amaçlamalıdır. 
Bir antrenör sporcunun başarısını düşünür. $\mathrm{Bu}$ nedenle olumlu bir grup atmosferi yaratmaya çalışmalı ve sporcularla kişilerarası ilişkiler kurmalıdır (Jowett ve Chaundy, 2004).

Antrenörün liderlik davranışı, belirlenen hedeflere doğru çabalayan bireyi ve grubu etkileme süreci olarak tanımlanabilir (Riemer ve Chelladurai, 1998).Antrenörün liderlik tarzı, sporcularıyla etkileşime girme şekline ve karar alma süreçlerine bağlıdır. Birçok sporda, sporcuların davranış değişiklikleri antrenörün liderliğinin doğrudan sonucu olarak kabul edilir (Barrow, 1977).Bir liderlik tarzının başarılı olabilmesi için antrenör, sporcunun özelliklerini belirleyebilmeli ve eğitim sürecini sadece bir bireyin ve grubun durumuna göre değil, aynı zamanda sporcunun hedeflerine ve gelişimine göre de liderlik tarzını sergileyebilmelidir. Antrenör sporcunun başarısını düşünür. $\mathrm{Bu}$ nedenle olumlu bir grup atmosferi yaratmaya çalışır ve sporcularla sıcak kişilerarası ilişkiler kurar(Jowett ve Chaundy, 2004). İyi bir antrenör sorumluluk almaya hazırdır ve aynı zamanda yaratıcı, güvenilir bir kişidir. Antrenörün liderlik davranışı ve belirli bir spor dalındaki antrenman süreci, öncelikli olarak seçici karar verme, bilgi transferi, motivasyonel teknikler bireyin veya grubun belirlenen hedeflere ulaşmaya yönelik olmalıdır (Arslan ve Uslu, 2014).

Liderler, liderlik yönelimlerini sergilerken grup veya takipçilerin ihtiyaçlarına göre davranış sergilerler. Bu davranışlar lider ve takipçileri ile içinde bulundukları durum ve değişen şartlara göre göz önünde bulundurularak sergilenmelidir. Bu durum spor ortamında antrenör, müsabaka şartlarına bağlı olarak ve sporcunun o anki çevresel ve psikolojik faktörlere bağlı olarak gereken liderlik yönelimi tarzını ortaya koymalıdır. Antrenör, sporcunun ihtiyacına cevap verebilmelidir. Antrenörlerin sergilemiş oldukları liderlik yönelimleri, takımın başarılı olmasında önemli bir unsurdur. Bu liderlik yönelimleri antrenör veya teknik direktörde olması gereken özelliklerdir. Teknik direktör veya antrenördeki liderlik özellikleri, kulüp yöneticileri ve teknik kadroyu bütünleştirici davranış tarzını oluşturup ve takım üzerindeki egemenliğini kurup, takımın istenen amaçlara ulaşmasında önderlik eder (Sevil, 1997). Antrenör, sporcuları yönlendirebilmek için çok boyutlu özelliklere sahip olması gerekir. Antrenör iyi bir sporcu yetiştirebilmesi için liderlik özelliklerini sergileyebilmeli ve sporcunun ihtiyaçlarını bilmelidir (Tozoğlu, 2003).

Bu bağlamda, yapılan çalışmada Sakarya ilinin Adapazarı ilçesindeki özel spor merkezlerinde bireysel ve takım sporlarında antrenörlük yapan bireylerin liderlik davranışları yönelimlerinin bazı değişkenlere göre belirlenmesi amaçlanmıştır.

\section{Yöntem}

\section{Araştırmanın Modeli}

Betimsel tipte olan bu çalışmanın amacı; Sakarya ilinin Adapazarı ilçesinde antrenörlük yapan bireylerin liderlik yönelimlerinin incelenmesidir. Bu araştırmanın yapılabilmesi için Kocaeli Üniversitesi Sosyal ve Beşeri Bilimler Etik Kurulu'nun 27/02/2020 tarihli, 2020/3 nolu ve 5 sira sayılı kararı ile etik kurul onayı alınmıştır.

\section{Örneklem ve Evren}

Araştırmanın evrenini Sakarya ilinin Adapazarı ilçesindeki özel spor merkezlerinde antrenörlük yapan bireyler, örneklemini ise rastgele yöntem ile seçilmiş 55 kadın ve 125 erkek olmak üzere toplam 180 kişi oluşturmaktadır. Araştırma, Sakarya ilinin Adapazarı ilçesindeki özel spor merkezleriyle sinırlıdır.

\section{Veri Toplama Araçları}

Araştırmada veri toplama aracı olarak antrenörlerin yaşı, cinsiyeti, gelir ve sosyo-ekonomik durumlarını belirlemeye yönelik soruların olduğu kişisel bilgi formunun yanı sıra Bolman ve Deal tarafindan (1990) yılında geliştirilen ve Dereli (2003) tarafindan Türkçeye uyarlanan "Liderlik Yönelimleri Ölçeği” kullanılmıştır. Ölçek toplam 32 sorudan oluşmakta ve 5'li likert tipindedir. Likert tipi, her zaman (5), sik sik (4) bazen (3) nadiren (2) hiçbir zaman (1) şeklinde 
Bireysel ve Takım Sporlarındaki Antrenörlerin Liderlik Davranışları Yönelimlerinin... 2629

değerlendirilmektedir. Ölçek 4 alt boyuttan "Karizmatik Liderlik" (Sembolik Çerçeve), "Dönüşümsel Liderlik" (Politik Çerçeve), "İnsana Yönelik Liderlik" (İnsan Kaynakları), ve "Yapısal Liderlik" (Yapısal Çerçeve) meydana gelmektedir. Liderlik yönelimlerinin alt boyutlarının Cronbach alpha değeri ise sırasıyla (0.760), (0.80), $(0.81),(0.79)$ olduğu belirtilmiştir (Dereli, 2003).

\section{Verilerin İstatistiksel Analizi}

Araştırmada elde edilen bulguların değerlendirilmesinde, SPSS 20.0 paket programı kullanılmıştır. Çalışma verilerinin değerlendirilmesinde; frekans, yüzde (\%), standart sapma gibi tanımlayıcı istatistiklerden yararlanılmıştır. Araştırma gönüllülük ilkesine dayandırılarak yapılmıştır. Araştırmaya katılmak isteyen antrenörlere araştırmanın amacı hakkında bilgi verilmiş ve araştırmaya katılmak isteyen antrenörlerin bilgi formu (cinsiyet, yaş, ekonomik durum) ve liderlik yönelimleri ölçeğini doldurulmaları istenmiştir. Ölçme araçlarını yanlış ya da eksik dolduranlar araştırma dişında tutulmuştur. Daha sonra geçerli ve kabul edilebilir 180 adet ölçek araştırmaya dahil edilmiştir. Normallik dağılımı Kolmogorov Smirnov testi ile yapılmıştır. Veriler normal dağılım gösterdiği için parametrik testler uygulanmış ve bağımsız değişkenler için ikili küme karşılaştırılmasında bağımsız $t$ testi, ikiden fazla karşılaştırmalar için Anova testi ve bulunan sonuçların doğru bir şekilde analiz edilmesi için Scheffe testi kullanılmıştır.

\section{Bulgular}

Tablo 1: Araştırmaya Katılan Antrenörlerin Cinsiyet, Yaş ve Ekonomik Durumuna İlişkin Frekans ve Yüzdelik Değerler

\begin{tabular}{cccc}
\hline & Değişkenler & $\mathbf{N}$ & \% \\
\hline \multirow{2}{*}{ Cinsiyet } & Kadın & 55 & 30.6 \\
& Erkek & 125 & 69.4 \\
& Toplam & 180 & 100.0 \\
\hline \multirow{3}{*}{ Yaş } & 25 -altı & 44 & 24.4 \\
& $26-35$ & 92 & 51.1 \\
& $36-45$ & 28 & 15.6 \\
Ekonomik Durum & 46 ve üzeri & 16 & 8.9 \\
& Toplam & 180 & 100.0 \\
\hline \multirow{3}{*}{ 2000tl ve altı } & $2001-2500$ tl & 29 & 20.0 \\
& $2501-3000 t 1$ & 48 & 16.1 \\
& 3001 ve üzeri & 67 & 26.7 \\
& Toplam & 180 & 37.2 \\
\hline
\end{tabular}

Araştırmaya katılan antrenörlerin cinsiyet değişkeni ve yüzdelik değerlerine bakıldığında; 55'inin (\%30.6) kadın, 125'inin (\%69.4) erkek olduğu görülmektedir. Yaş değişkenine bakıldığında, 44'ünün (\%24.4) 25 yaş-altı, 92'sinin (\%51.1) 26-35 yaş, 28'inin (\%15.6) 36-45 yaş, 16 'sının (\%8.9) 46 yaş ve üzeri olduğu görülmektedir. Ekonomik durum değişkenine bakıldığında, 36'sinin (\%20.0) 2000tl ve alt1, 29'unun (\%16.) 2001-2500tl, 48'inin (\%26.7) 2501-3000tl, 67'sinin (\%37.2) 3001 tl ve üzeri olduğu görülmektedir. 
Tablo 2: Araştırmaya Katılan Antrenörlerin Cinsiyet Durumuna Göre Liderlik Yönelimleri Ölçeği Puanlarının Analizi (T Testi)

\begin{tabular}{|c|c|c|c|c|c|c|}
\hline & Cinsiyet & $\mathbf{N}$ & $\mathbf{X}$ & SS & $\mathbf{T}$ & $\mathbf{P}$ \\
\hline İnsana & Kadın & 55 & 33.90 & 3.29 & \multirow[b]{2}{*}{1.092} & \multirow[b]{2}{*}{0.327} \\
\hline $\begin{array}{c}\text { Yönelik } \\
\text { Liderlik }\end{array}$ & Erkek & 125 & 34.09 & 4.25 & & \\
\hline Yapıya & Kadın & 55 & 33.67 & 3.78 & \multirow[b]{2}{*}{,707 } & \multirow[b]{2}{*}{0.672} \\
\hline $\begin{array}{l}\text { Yönelik } \\
\text { Liderlik }\end{array}$ & Erkek & 125 & 33.92 & 4.34 & & \\
\hline Karizmatik & Kadın & 55 & 44.34 & 4.21 & \multirow[b]{2}{*}{, 575} & \multirow[b]{2}{*}{0.990} \\
\hline Liderlik & Erkek & 125 & 43.92 & 4.75 & & \\
\hline Dönüşümsel & Kadın & 55 & 31.05 & 4.21 & & \\
\hline Liderlik & Erkek & 125 & 31.48 & 5.34 & 966 & 0.327 \\
\hline
\end{tabular}

Cinsiyet değişkenine göre liderlik yönelimleri puan ortalamaları incelendiğinde; insana yönelik liderlikte kadınların $33.90 \pm 3.29$ erkeklerin ise $34.09 \pm 4.25$, yapıya yönelik liderlikte kadınların $33.67 \pm 3.78$ erkeklerin ise $33.92 \pm 4.34$, karizmatik liderlikte kadınların $44.34 \pm 4.21$ erkeklerin ise $43.92 \pm 4.74$, dönüşümsel liderlikte kadınların $31.05 \pm 4.21$ erkeklerin ise $31.48 \pm 5.34$ olduğu görülmektedir. Liderlik yönelimleri puanlarına bakıldığında cinsiyete göre anlamlı farklılık olmamasına rağmen karizmatik liderlik yöneliminin puanı diğer liderlik yönelimlerinin puanlarına göre yüksek olduğu sonucu bulunmuştur ( $\mathrm{p}>0.05$ ).

Tablo 3: Antrenörlerin Yaş Durumuna Göre Liderlik Yönelimleri Düzeyi Varyans Analizi Sonuçları (One Way Anova)

\begin{tabular}{|c|c|c|c|c|c|c|}
\hline & Yaş & $\mathbf{N}$ & $\mathbf{X}$ & SS & $\mathbf{F}$ & $\mathbf{P}$ \\
\hline \multirow{4}{*}{$\begin{array}{l}\text { İnsana Yönelik } \\
\text { Liderlik }\end{array}$} & 25 yaş ve altı & 44 & 31.52 & 5.30 & \multirow{4}{*}{,086 } & \multirow{4}{*}{,968 } \\
\hline & $26-35$ & 92 & 31.73 & 3.30 & & \\
\hline & $36-45$ & 28 & 29.28 & 3.82 & & \\
\hline & $\begin{array}{c}46 \text { yaş ve } \\
\text { üzeri }\end{array}$ & 16 & 32.25 & 3.90 & & \\
\hline \multirow{4}{*}{$\begin{array}{c}\text { Yapıya Yönelik } \\
\text { Liderlik }\end{array}$} & 25 yaş ve altı & 44 & 33.65 & 5.29 & \multirow{4}{*}{,854 } & \multirow{4}{*}{,466 } \\
\hline & $26-35$ & 92 & 33.67 & 3.77 & & \\
\hline & $36-45$ & 28 & 33.82 & 3.87 & & \\
\hline & $\begin{array}{c}46 \text { yaş ve } \\
\text { üzeri }\end{array}$ & 16 & 35.43 & 3.34 & & \\
\hline \multirow{4}{*}{$\begin{array}{c}\text { Karizmatik } \\
\text { Liderlik }\end{array}$} & 25 yaş ve altı & 44 & 43.61 & 5.00 & \multirow{4}{*}{1.195} & \multirow{4}{*}{,313 } \\
\hline & $26-35$ & 92 & 44.52 & 4.46 & & \\
\hline & $36-45$ & 28 & 42.85 & 4.36 & & \\
\hline & $\begin{array}{c}46 \text { yaş ve } \\
\text { üzeri }\end{array}$ & 16 & 44.68 & 4.39 & & \\
\hline \multirow{4}{*}{$\begin{array}{l}\text { Dönüșümsel } \\
\text { Liderlik }\end{array}$} & 25 yaş ve altı & 44 & 31.52 & 5.71 & \multirow{4}{*}{1.986} & \multirow{4}{*}{,118 } \\
\hline & $26-35$ & 92 & 31.73 & 4.78 & & \\
\hline & $36-45$ & 28 & 29.28 & 4.56 & & \\
\hline & $\begin{array}{c}46 \text { yaş ve } \\
\text { üzeri }\end{array}$ & 16 & 32.25 & 4.56 & & \\
\hline
\end{tabular}


Bireysel ve Takım Sporlarındaki Antrenörlerin Liderlik Davranışları Yönelimlerinin... 2631

İnsana yönelik liderlik yönelimlerinde yaş değişkenine bakıldığında 25 yaş ve altı (31.52 \pm 5.30$)$, $26-35$ yaş $(31.73 \pm 3.30), 36-45$ yaş $(29.28 \pm 3.82)$, 46 yaş ve üzeri $(32.25 \pm 3.90)$ olduğu görülmektedir. Yaş değişkenine göre, insana yönelik liderlik ölçeği puan ortalamasına bakıldığında anlamlı farklılık olmadığı görülmektedir ( $\mathrm{p}=0.968 ; \mathrm{p}>0.05)$.

Yapıya yönelik liderlik yönelimlerinde yaş değişkenine bakıldığında 25 yaş ve altı (33.65 \pm 5.29$)$, 26-35 yaş (33.67 \pm 3.77$), 36-45$ yaş $(33.82 \pm 3.87), 46$ yaş ve üzeri $(35.43 \pm 3.34)$ olduğu görülmektedir. Yaş değişkenine göre, yapıya yönelik liderlik ölçeği puan ortalamasına bakıldığında istatistiksel olarak anlamlı farklılık tespit edilmemiştir $(\mathrm{p}=0.466 ; \mathrm{p}>0.05)$.

Karizmatik liderlik yönelimlerinde yaş değişkenine bakıldığında; 25 yaş ve altı (43.61 \pm 5.00$), 26-35$ yaş (44.52 \pm 4.46$), 36-45$ yaş (42.85 44.36$), 46$ yaş ve üzeri (44.68 \pm 4.39$)$ olduğu görülmektedir. Yaş değişkenine göre, karizmatik liderlik ölçeği puan ortalamasına bakıldığında istatistiksel olarak anlamlı farklı1ık olmamasına rağmen karizmatik liderlik yöneliminin puanı diğer liderlik yönelimlerine göre yüksek olduğu görülmektedir $(\mathrm{p}=0.313 ; \mathrm{p}>0.05)$.

Dönüşümsel liderlik yönelimlerinde yaş değişkenine bakıldığında; 25 yaş ve altı (31.52 \pm 5.71$), 26-35$ yaş $(31.73 \pm 4.78), 36-45$ yaş $(29.28 \pm 4.56), 46$ yaş ve üzeri $(32.25 \pm 4.56)$ olduğu görülmektedir. Yaş değişkenine göre, dönüşümsel liderlik ölçeği puan ortalamasına bakıldığında istatistiksel olarak anlamlı farklılık tespit edilmemiştir $(p=0.118 ; p>0.05)$.

Tablo 4: Araştırmaya Katılan Antrenörlerin Ekonomik Durumuna Göre Liderlik Yönelimleri Ölçeği Puanlarının One Way Anova Sonuçları

\begin{tabular}{|c|c|c|c|c|c|c|c|}
\hline & $\begin{array}{c}\text { Ekonomik } \\
\text { Durum }\end{array}$ & $\mathbf{N}$ & $\mathbf{x}$ & SS & $\mathbf{F}$ & $\mathbf{P}$ & Scheffe \\
\hline \multirow{4}{*}{$\begin{array}{c}\text { İnsana } \\
\text { Yönelik } \\
\text { Liderlik }\end{array}$} & 2000tl- alt1 & 36 & 34.44 & 3.68 & & & \\
\hline & 2001-2500tl & 29 & 32.37 & 5.72 & & & \\
\hline & 2501-3000tl & 48 & 34.52 & 3.01 & 2.116 & .100 & \\
\hline & 3001tl- üzeri & 67 & 34.19 & 3.71 & & & \\
\hline \multirow{4}{*}{$\begin{array}{c}\text { Yapıya } \\
\text { Yönelik } \\
\text { Liderlik }\end{array}$} & 2000tl- alt1 ${ }^{\mathbf{a}}$ & 36 & 33.97 & 3.44 & & & \\
\hline & $2001-2500 \mathrm{tl}^{\mathrm{b}}$ & 29 & 31.44 & 6.34 & & & \\
\hline & $2501-3000 \mathrm{tl} \mathrm{l}^{\mathrm{c}}$ & 48 & 34.47 & 3.41 & & & b-c \\
\hline & 3001-üzeri ${ }^{\mathrm{d}}$ & 67 & 34.37 & 3.53 & 4.128 & $.007^{*}$ & b-d \\
\hline \multirow{4}{*}{$\begin{array}{c}\text { Karizmatik } \\
\text { Liderlik }\end{array}$} & 2000tl-altt ${ }^{\mathrm{a}}$ & 36 & 43.91 & 4.12 & & & \\
\hline & $2001-2500 t t^{b}$ & 29 & 41.65 & 5.25 & & & \\
\hline & $2501-3000 \mathrm{tl}^{\mathrm{c}}$ & 48 & 45.64 & 4.12 & 4.881 & $.003 *$ & b-c \\
\hline & 3001-üzeri ${ }^{\mathrm{d}}$ & 67 & 44.02 & 4.45 & & & \\
\hline \multirow{4}{*}{$\begin{array}{l}\text { Dönüşümsel } \\
\text { Liderlik }\end{array}$} & 2000tl-alt1 & 36 & 31.91 & 4.55 & & & \\
\hline & 2001-2500tl & 29 & 29.82 & 5.89 & & & \\
\hline & 2501-3000tl & 48 & 32.00 & 4.96 & 1.330 & .266 & \\
\hline & 3001tl-üzeri & 67 & 31.23 & 4.87 & & & \\
\hline
\end{tabular}

Ekonomik durum değişkenine göre insana yönelik liderlik ölçeği puan ortalamaları incelendiğinde; 2000tl-altı (34.44 \pm 3.68$)$ 2001-2500tl (32.37 \pm 5.72$)$ 2501-3000tl (34.52 \pm 3.01$)$, 
3001tl-üzeri (34.19 \pm 3.71$)$ olduğu görülmektedir. Ekonomik durum değişkenine göre, liderlik puan ortalamalarına bakıldığında anlamlı bir farklılık tespit edilmediği görülmüştür ( $\mathrm{p}>0.05)$.

Yapıya yönelik liderlik alt boyutunda ekonomik durum değişkeninin puan ortalamalarına

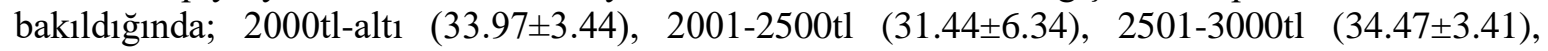
3001 tl-üzeri (34.37 \pm 3.53$)$ olduğu görülmektedir. Ekonomik durum değişkenine göre, yapıya yönelik liderlik ölçeği puan ortalamasına bakıldığında istatistiksel olarak anlamlı bir farklılık tespit edilmiştir $(\mathrm{p}=0.007 ; \mathrm{p}<0.05)$. Bu farklılığın hangi ekonomik durumda olduğunu belirlemek amaciyla yapilan Scheffe testi analizinde 2501-3000tl ile 3001tl-üzeri ekonomik gelire sahip olan antrenörlerin puan ortalamasının, 2001-2500tl gelire sahip olan antrenörlerin puanlarından daha yüksek olduğu görülmüştür.

Karizmatik liderlik ölçeği puan ortalamaları incelendiğinde; 2000tl-altı (43.91 \pm 4.12$)$, 2001-2500tl (41.65 \pm 5.25$), \quad 2500-300 t l \quad(45.64 \pm 4.12), \quad 3001$ tl-üzeri $\quad(44.02 \pm 4.45)$ olduğu görülmektedir. Ekonomik durum değişkenine göre, karizmatik liderlik alt boyutu ölçeği puan ortalamasına bakıldığında istatistiksel olarak anlamlı farklılık tespit edilmiştir $(\mathrm{p}=0.003 ; \mathrm{p}<0.05)$. $\mathrm{Bu}$ farklılığın hangi ekonomik durumda olduğunu belirlemek amaciyla yapılan Scheffe testi analizinde 2501-3000tl gelire sahip olan antrenörlerin puan ortalamasının 2001-2500 tl gelire sahip olan antrenörlerin puanlarından daha yüksek olduğu bulunmuştur.

Dönüşümsel liderlik ölçeği puan ortalamaları incelendiğinde; 2000tl-altı (31.91 \pm 4.55$)$, 2001-2500tl (29.82 \pm 5.89$), \quad 2501-3000 t l \quad(32.00 \pm 4.96), \quad 3001$ tl-üzeri (31.23 \pm 4.87$)$ olduğu görülmektedir. Ekonomik durum değişkenine göre, dönüşümsel liderlik alt boyut puan ölçeği ortalamasına bakıldığında istatistiksel olarak anlamlı farklılık tespit edilmemiştir $(\mathrm{p}=0.266$; $\mathrm{p}>0.05)$.

\section{Tartışma ve Sonuç}

Bireysel ve takım sporlarındaki antrenörlerin liderlik davranışları yönelimlerinin belirlenmesi amacıyla yapılan çalışmada; Sakarya ilinin Adapazarı ilçesinde antrenörlük yapan bireylerin liderlik yönelimlerine ait puanlara bakıldığında, cinsiyet değişkenine göre anlamlı bir farklı1ık bulunmamıştır ( $>0.05$ ). Bunun nedeni, kadın ve erkek antrenör ayrımı olmadan tüm antrenörlerin belirlenen hedeflere ulaşmasına yönelik sporcuları için etkili olan liderlik davranışlarını taşımasının önemli olduğuna bağlanabilinir. Ayrıca, liderliğin çeşitli eğitim programlarıyla geliştirilebilen bir özellik olabileceği düşünülebilinir. Konuyla ilgili alan yazın tarandığında çalışmamızla paralellik gösteren çalışmaların olduğu görülmektedir (Atar ve Özbek, 2009; Semiz, 2011; Burks, 1992; Kolb, 1999; Eagly ve Johnson, 1990; Engen ve Willemsen, 2000; Güngör, 2016; Özkan, 2012). Aydın ve ark. (2016) yılında yaptıkları çalışmada spor bilimleri fakültesinde eğitim gören öğrencilerin cinsiyet faktöründe yapısal liderlik, karizmatik liderlik ve dönüşümsel liderlikte anlamlı farklılık bulunmazken, insana yönelik liderlikte ise kadınların lehine anlamlı farklılık olduğu sonucunu bulmuşlar ve bu farklılığında kadınların erkeklere göre empati özelliklerinin daha yüksek olduğu aynı zamanda kadınların gerek işbirliği gerekse insanların fikirlerine önem verdiklerinden dolayı bu sonucun alınmasında etkili olduğunu düşünmüşlerdir. Durmuş'un (2011) yılında ilkokul ve ortaokul öğrencileri üzerinde yapmış olduğu çalışmada ise yapısal liderlik, insana yönelik lider ve dönüşümsel liderlikte kadınların lehine anlamlı bir ilişki bulunmuştur. Taşgın ve ark. (2007) yılında bireysel antrenörler üzerinde yaptığı çalışmada ise yapısal, dönüşümsel ve karizmatik liderlik yönelimlerinde anlamlı farklılık bulunmazken insana yönelik liderlik tarzından anlamlı farklılık bulunmamıştır. Çelik ve Sünbül (2008) yılında üniversite öğrencileri üzerinde yaptığı çalışmada cinsiyet faktöründe anlamlı bir farklılık bulunmamıştır. Bu bulguların aksine Efekan'ın (2007) yılında kara harp öğrencileri üzerinde yaptığı çalışmada cinsiyet faktöründe karizmatik ve yapısal liderlikte erkeklerin lehine anlamlı farklılık bulunmuş ve bunun sebebinin de kara harp okulundaki öğrencilerin komutanlarıyla sürekli etkileşim içinden olduklarından dolayı bu sonucu alınmasında etkili olduğu belirtilmiştir (Turan ve 
ark., 2016). Literatüre bakıldığında liderlik tarzlarının cinsiyet değişkeninde anlamlı fark bulan çalışmaların sınırlı olduğu görülmüştür. Bu ulaşılan durum çalışmamızla paralellik göstermektedir.

Yaş değişkenine göre liderlik yönelimleri ölçeği puan ortalamalanı incelendiğinde; insana yönelik, karizmatik, dönüşümsel ve yapısal liderlik yönelimi alt boyut puanlarında istatistiksel olarak anlamlı bir farklılık bulunmamıştır ( $\mathrm{p}>0.05$ ). İlgili alan yazın taradığında Gözcü ve ark. (2019) yılında spor merkezlerinde çalışan bireylerin görev aldıkları kurumlardaki yöneticilerin liderlik tarzlarında yaş faktörünün liderlik algısında anlamlı bir fark tespit edilmemiştir. Köleşoğlu (2009) yılında yapmış olduğu çalışmada ise ilkokul öğretmenlerinin liderlik yönelimlerinin incelendiği çalıșmasında yaș değișkenleri arasında anlamlı bir fark bulunmadığını tespit etmiștir. Çalışmada yaş değişkeninde anlamlı bir farklılığın bulunmamasının ( $\mathrm{p}>0.05)$ nedeni, liderliğin yaşa bağlı olarak gelişen bir özellik olmadığına ve araştırmaya katılan antrenörlerin liderlik özelliklerini deneyimleyebilecekleri bir ortamın bulunmamasına bağlanabilinir. Konuyla ilgili alan yazın tarandığında (Aytekin, 2014; Atçı, 2018; Mcardle, 2008; Dereli, 2003) yapmış olduğu çalışmada ise yaş faktörünün liderlik yönelimlerinde anlamlı farklılık bulunmuş ve bu farklılığında bireyin yaşının artmasına bağlı olarak deneyimlerinin de geliştiği ileri sürülmektedir.

Ekonomik durum değişkeni incelendiğinde, karizmatik ve yapıya yönelik liderlikte anlamlı bir farklılık bulunmuștur $(\mathrm{p}<0.05)$. Bu sonucun nedenini, liderin vizyonunu gerçekleştirebilmesi için ekonomik durumun bireye daha fazla imkân oluşturduğu olasılığına bağlamak mümkün olabilir. Yapıya yönelik liderliğin alt boyutunda anlamlı bir farklılık bulunmuştur $(p<0.05)$. Bunun nedenini de antrenörün içinde bulunduğu çalıșma koșullarından memnun olması durumu ile ilișkilendirilebileceği düşünülebilinir. Yapılan Scheffe testi sonucunda yapıya yönelik liderlikte 2501-3000tl ve 3001tl-üzeri ekonomik gelire sahip olan antrenörlerin puanlar1 2001-2500tl ekonomik gelire sahip olan antrenörlerin puanlarından daha yüksek olduğu görülmüştür. Ayrıca karizmatik liderlik alt boyutunda ise 2501-3000tl gelire sahip olan antrenörlerin puanlar1 20012500tl gelire sahip olan antrenörlerin puanlarından daha yüksek olduğu görülmektedir. Tokmak (2018) yöneticilerin hizmetkar liderlik tarzlarının çalışan personellerin algılama düzeyleri, çalışanların demografik özellikleri baz alarak yaptığı çalışmada gelir durumunun liderlik algısı ile ilgili anlamlı fark bularak araştırmamızı kısmi düzeyde desteklemektedir. Atçı'nın (2018) yılında ortaokul öğretmenlerinin ekonomik durum değişkeninde anlamlı farklılık olduğu sonucunu bulmuş ve bu farklılığında ekonomik durumun artmasına bağlı olarak öğretmenlerinde liderlik özelliklerinin arttığı sonucunu tespit etmiştir. Toklu'nun (2010) yılında yapmış olduğu çalışmada ise ekonomik durumun antrenörlerin liderlik özelliklerini etkilemediği sonucunu bulmuştur.

$\mathrm{Bu}$ çalışmada, özel spor merkezlerinde antrenörlük yapan bireylerin liderlik yönelimlerinin gelişiminde yapıya yönelik ve karizmatik liderlik özelliklerinin ekonomik duruma bağlı olarak etkilendiği ortaya çıkmış olup karizmatik ve yapıya yönelik liderliğin gelişiminde antrenörlerin güçlü bir vizyon oluşturabilmesi için emir komuta, iş bölümü gibi özelliklerinin gelişebilmesinde de ekonomik durumun önemli olduğu sonucuna varılmıştır. Bu bağlamda, bireysel ve takım sporlarında antrenörlük yapan bireylerin eğitim verilen yaş grubuna, cinsiyetine, gelişim düzeyine, bireysel farklılıklarına ve branşın özelliğine uygun olarak liderlik davranışları yönelimlerinin nasıl olması gerektiği ve bunu uygulama aşamasında nelere dikkat edilmesi konusunda sistemli ve düzenli eğitimlerin verilmesinin faydalı olabileceği düşünülmektedir. 


\section{Kaynakça}

Arslan, H., \& Uslu, B. (2013). Öğretmen adaylarının liderlik yönelimlerinin incelenmesi. $e$ uluslararası eğitim araştırmaları dergisi, 5(1), 42-60.

Atar, E., \& Özbek, O. (2009). Beden eğitimi ve spor yüksekokulu öğrencilerinin liderlik davranışları. Spormetre Beden Eğitimi ve Spor Bilimleri Dergisi, 7(2), 51-59.

Atçı, H. B. (2018). Ortaokul öğretmenlerinin liderlik ve rol çatışmaları. Yayımlanmamış yüksek lisans tezi. Yeditepe Üniversitesi, Sosyal Bilimler Enstitüsü, İstanbul.

Aydın, R., Bozkuş, T., \& Kul, M. (2016). Beden eğitimi ve spor yüksekokullarındaki öğrencilerin liderlik özelliklerinin cinsiyet değişkenine göre incelenmesi. International Journal Of Sport Culture and Science, 4 (Special Issue 1), 122-131.

Aytekin, H. (2014). Ortaöğretim okulu müdürlerinin ögrretmenler tarafindan algllanan durumsal liderlik stilleri ile ögretimsel liderlik rolleri arasındaki ilişkinin incelenmesi. Yayımlanmamış Yüksek Lisans Tezi, Yeditepe Üniversitesi, Sosyal Bilimler Enstitüsü, İstanbul.

Barrow, J. C. (1977). The variables of leadership: A review and conceptual framework. Academy of management Review, 2(2), 231-251.

Bolman L.G. \& Deal, T.E. (1990). Leadership orientations. Retrieved March 18, 2002 from the World Wide Web.

Burks, T. D. (1992). The use of organizational frames in leadership development (Doctoral dissertation, Peabody College For Teachers of Vanderbilt University, 1992). Dissertation Abstracts International, 53, 1413A.

Cengiz, R. \& Güllü, S. (2018). Spor bilimleri fakültesi öğrencilerinin liderlik yönelimleri ile fiziksel sayg1 düzeylerinin incelenmesi. Gaziantep Üniversitesi Spor Bilimleri Dergisi, 3 (4): 94-108.

Chelladurai, P. (1978). A Contingency model of leadership in athletics (Unpublished doctoral dissertation). Canada: University of Waterloo.

Chelladurai, P. (1984). Discrepancy between preferences and perceptions of leadership behavior and satisfaction of athletes in varying sports. Journal of Sport and Exercise Psychology, 6(1), 27-41.

Cotterill, S. T., \& Fransen, K. (2016). Athlete leadership in sport teams: Current understanding and future directions. International Review of Sport and Exercise Psychology, 9(1), 116133.

Çelik, C., \& Sünbül, Ö. (2008). Liderlik algılamalarında eğitim ve cinsiyet faktörü: Mersin ilinde bir alan araştırması. Suleyman Demirel University Journal of Faculty of Economics \& Administrative Sciences, 13(3).

Dereli, M. (2003). Illköğretim okulu müdürlerinin liderlik stilleri üzerine bir araştırma.Yüksek Lisans Tezi, Orta Doğu Teknik Üniversitesi Eğitim Fakültesi.

Doğan, O. (2015). Spor psikolojisi. Detay Yayıncılık.

Durmuş, Ö. (2011). İlköğretim ve lise öğrencilerinde görülen liderlik davranışlarının araştırılması. Yayımlanmamış Yüksek Lisans Tezi, Çanakkale Onsekiz Mart Üniversitesi Sosyal Bilimler Enstitüsü, Çanakkale.

Eagly, A. H., \&Johnson, B. T. (1990). Gender and leadership style: A metaanalysis. Psychological Bulletin, 108(2), 233. 
Bireysel ve Takım Sporlarındaki Antrenörlerin Liderlik Davranışları Yönelimlerinin... 2635

Efekan, H. (2007). Kara Harp Okulu olimpik spor branşlarında yapılan bireysel sporlar ile takım sporlarının Harbiyelilerin liderlik özelliklerine să̆ladı̆ğ etkilerin incelenmesi. Yayınlanmamış yüksek lisans tezi, Gazi Üniversitesi, Sağlık Bilimleri Enstitüsü, Ankara.

Engen, M. L., \& Willemsen, T. M. (2000). Gender and leadership styles: A review of the past decade. WORC Paper 00.10, 9, 1-33.

Gould, D., Tuffey, S., Loehr, J., \& Udry, E. (1996). Burnout in competitive junior tennis players: I. A quantitative psychological assessment. The Sport Psychologist, 10(4), 322-340.

Gözcü, H., Çiftçi, S., \& Aleyna, K. (2019). Spor merkezi çalışanlarının yönetici liderlik tarzı ile ilgili algılarının araştıılması. Spor ve Rekreasyon Araştırmaları Dergisi, 1(1), 48-57.

Güngör, N. B. (2016). Beden eğitimi öğretmen adaylarının epistemolojik inançları ile liderlik özellikleri arasındaki ilişkinin incelenmesi. Yüksek Lisans Tezi, Gazi Üniversitesi, Eğitim Fakültesi, Ankara.

Jowett, S., \& Chaundy, V. (2004). An investigation into the impact of coach leadership and coach-athlete relationship on group cohesion. Group Dynamics: Theory, Research, and Practice, 8(4), 302.

Kajtna, T., Tušak, M., Masten, R., \& Bednarik, J. (2007). Coach: sports psychology and coaches. Faculty of Sports, Institute of Sports.

Katz, D., \& Kahn, R. L. (1978). The social psychology of organizations (Vol. 2, p. 528). New York: Wiley.

Kolb, D. A. (2007). The Kolb learning style inventory. Boston, MA: Hay Resources Direct.

Köleşoğlu, G. (2009). İlköğretim öğretmenlerinin liderlik özellikleri ile iletişim becerileri arasındaki ilişki İstanbul İli Beyoğlu İlköğretim Okullarında bir uygulama. Yüksek Lisans Tezi, Beykent Üniversitesi Sosyal Bilimler Enstitüsü, İstanbul.

Mcardle, M. K. (2008). Leadership orientations of community college presidents and the administrators who report to them: a frame analysis. Unpublished doctoral dissertation, University of Central Florida, College of Education, Florida

Özkan, N. Ö. (2012). Hemşirelik ögrrencilerinin liderlik yönelimleri ve motivasyon düzeylerinin incelenmesi. Doktora Tezi, İstanbul Bilim Üniversitesi, Sağlık Bilimleri Enstitüsü, Hemşirelik Anabilim Dalı, İstanbul.

Riemer, H. A., \& Chelladurai, P. (1998). Development of the athlete satisfaction questionnaire (ASQ). Journal of sport and exercise psychology, 20(2), 127-156.

Semiz, H. (2011). Ortaöğretim öğrencilerinde sporun liderlik üzerine etkisi: Hendek örneği. Yayımlanmamış Yüksek Lisans Tezi, Sakarya Üniversitesi, Eğitim Bilimleri Enstitüsü, Sakarya.

Senger, K., \& Kaya, H. İ. (2017). Öğretmenlerin Liderlik Yönelim Algılarının Yaş ve Cinsiyet Değişkenleri Açısından İncelenmesi. Turan: Stratejik Arastirmalar Merkezi, 9(36), 168175 .

Sevil, T. (1997). Sporda liderlik davranışlarının takım başarısı üzerindeki etkileri. Yüksek Lisans Tezi, Anadolu Üniversitesi, Sağlık Bilimleri Enstitüsü, Beden Eğitimi ve Spor Anabilim Dalı, Eskişehir. 
Szedlak, C., Smith, M. J., Day, M. C., \& Greenlees, I. A. (2015). Effective behaviours of strength and conditioning coaches as perceived by athletes. International Journal of Sports Science \& Coaching, 10(5), 967-984.

Şahin, M. (2011). Alp disiplini kayak antrenörlerinin çeşitli fiziksel ve fizyolojik parametrelerinin değerlendirilmesi. Uluslararası Hakemli Akademik Sosyal Bilimler Dergisi, 1(1), 108-113.

Taşgın, Ö. B., \& Tekin, A. M., (2007). Badminton anternörlerinin çeşitli değişkenlere göre liderlik özelliklerinin incelenmesi. Selçuk Üniversitesi Sosyal Bilimler Enstitüsü Dergisi,3, 14-15.

Tekin, A., \& Zorba, E. (2001). Spor ve rekreasyon organizasyonlarında etkili liderlik. Beden Eğitimi ve Spor Bilimleri Dergisi, 1(2).

Trninic, M., Papić, V., \& Trninic, V. (2009). Influence of coach's leadership behaviour and process of training on performance and competition efficacy in elite sport. Acta kinesiologica, 3(1), 18-25.

Toklu, O. (2010). Tenis antrenörlerinde liderlik özellikleri ve öz yeterlik arasındaki ilişkinin belirlenmesi. Yüksek Lisans Tezi. Selçuk Üniversitesi Sağlık Bilimleri Enstitüsü, Konya.

Tokmak, M. (2018). Yöneticilerin hizmetkâr liderlik davranışlarının çalışanlar tarafından algilanma düzeylerine yönelik bir araştırma. Ataturk University Journal Of Economics \& Administrative Sciences, 32(4),40-45.

Tozoğlu, E. (2003). Farklı spor dallarında görev alan antrenörlerin liderlik özellikleri ve bu özelliklerinin bazı değişkenlerle ilişkileri. Yayınlanmamış Yüksek Lisans Tezi, Atatürk Üniversitesi, Sosyal Bilimler Enstitüsü, Erzurum.

Turan, M. B., Erol, Z., \& Karaoğlu, B. (2016). Beden eğitimi ve spor öğretmenliği bölümünde okuyan öğrencilerin liderlik düzeylerinin öğretmenlik mesleği yordama gücünün incelenmesi. İstanbul Üniversitesi Spor Bilimleri Dergisi, 6(3), 71-78.

Williams, J. M., \& Krane, V. (Eds.). (2015). Understanding and using imagery in sport. Applied sport psychology: Personal growth for peak performance, 240-273. 